\title{
The pathogenesis of insulin resistance: integrating signaling pathways and substrate flux
}

\author{
Varman T. Samuel ${ }^{1,2}$ and Gerald I. Shulman ${ }^{1,3,4}$ \\ 'Department of Medicine, Yale University School of Medicine, New Haven, Connecticut, USA. ${ }^{2}$ Veterans Affairs Medical Center, West Haven, Connecticut, USA. ${ }^{3}$ Department of Cellular and Molecular \\ Physiology and ${ }^{4}$ Howard Hughes Medical Institute, Yale University School of Medicine, New Haven, Connecticut, USA.
}

\begin{abstract}
Insulin resistance arises when the nutrient storage pathways evolved to maximize efficient energy utilization are exposed to chronic energy surplus. Ectopic lipid accumulation in liver and skeletal muscle triggers pathways that impair insulin signaling, leading to reduced muscle glucose uptake and decreased hepatic glycogen synthesis. Muscle insulin resistance, due to ectopic lipid, precedes liver insulin resistance and diverts ingested glucose to the liver, resulting in increased hepatic de novo lipogenesis and hyperlipidemia. Subsequent macrophage infiltration into white adipose tissue (WAT) leads to increased lipolysis, which further increases hepatic triglyceride synthesis and hyperlipidemia due to increased fatty acid esterification. Macrophage-induced WAT lipolysis also stimulates hepatic gluconeogenesis, promoting fasting and postprandial hyperglycemia through increased fatty acid delivery to the liver, which results in increased hepatic acetylCoA content, a potent activator of pyruvate carboxylase, and increased glycerol conversion to glucose. These substrateregulated processes are mostly independent of insulin signaling in the liver but are dependent on insulin signaling in WAT, which becomes defective with inflammation. Therapies that decrease ectopic lipid storage and diminish macrophageinduced WAT lipolysis will reverse the root causes of type 2 diabetes.
\end{abstract}

In most natural habitats, calorie availability is scarce and unpredictable, necessitating the evolution of systems for the efficient storage and utilization of energy. But in our modern, mechanized society, caloric demands are minimized, while highly palatable, calorie-dense foods and beverages are readily available. These changes have fostered the current pandemic of obesity and comorbid conditions of nonalcoholic fatty liver disease (NAFLD), atherosclerosis, and type 2 diabetes (T2D). Insulin resistance is a common feature of all these diseases, and much effort has been invested in delineating the pathogenesis of insulin resistance. We will first review the role of insulin and nutrients (specifically glucose and fatty acids) in nutrient storage (Figure 1) and then use this framework to explore the various defects that give rise to insulin resistance and T2D (Figure 2).

\section{Postprandial hepatic glucose and lipid metabolism}

The simple act of eating rapidly shifts hepatic glucose metabolism from glucose production to glucose storage, a complex transition regulated by multiple factors including nutrients, alterations in pancreatic and enteric hormones, and neural regulation. Insulin is a crucial regulator of this transition, primarily by activating glycogen synthase (1). The importance of insulin is seen in patients with type 1 diabetes (T1D), who only synthesize one-third the amount of hepatic glycogen as control subjects after a mixed meal (2). Yet, hyperinsulinemia, in the absence of hyperglycemia, promotes hepatic glycogen cycling with minimal net hepatic glycogen syn-

Conflict of interest: The authors have declared that no conflict of interest exists Reference information: / Clin Invest. 2016;126(1):12-22. doi:10.1172/JCI77812. thesis (1). And hyperglycemia, without hyperinsulinemia, inhibits hepatic glycogenolysis via glucose-mediated inhibition of glycogen phosphorylase (3), with minimal net hepatic glycogen synthesis (1). The combination of hyperinsulinemia and hyperglycemia maximizes net hepatic glycogen synthesis (1). Other nutrients further optimize net hepatic glycogen synthesis, such as activation of glucokinase by catalytic quantities of fructose (4).

Hepatic insulin action requires a coordinated relay of intracellular signals (Figure 1 and ref. 5). Insulin activates the insulin receptor tyrosine kinase (IRTK), with subsequent activation of kinases including 3-phosphoinositide-dependent kinase-1 (PDK1) and mTORC2 (6), which converge on Akt phosphorylation (6-8). The pattern of insulin delivery may also impact Akt phosphorylation, with pulsatile portal delivery (which better mimics physiology) leading to greater activation than continuous, fixed insulin delivery (9). Activation of Akt is the integral result of multiple inputs to regulate hepatic glucose and lipid metabolism. This model has been used to explain how insulin suppresses hepatic glucose production via (i) lowering expression of gluconeogenic enzymes via phosphorylation and nuclear exclusion of FOXO1 and (ii) inactivation of glycogen synthase kinase $3 \beta$ (GSK3 $\beta$ ), which permits the activation of glycogen synthase.

Recent studies challenge the primacy of the Akt/GSK3 $\beta$ / glycogen synthase branch in the regulation of glycogen synthesis (10). Hepatic insulin resistance in mice lacking both hepatic Akt1 and Akt2 (double liver KO; DLKO) was essentially normalized by the additional deletion of FOXO1, in a triple KO (TLKO) mouse model (11). Remarkably, the TLKO mice exhibited relatively normal fasting and postprandial glucose tolerance (10). This suggests that FOXO1 deletion enables other mechanisms to normalize hepatic glucose metabolism. Finally, Akt2-mediated 


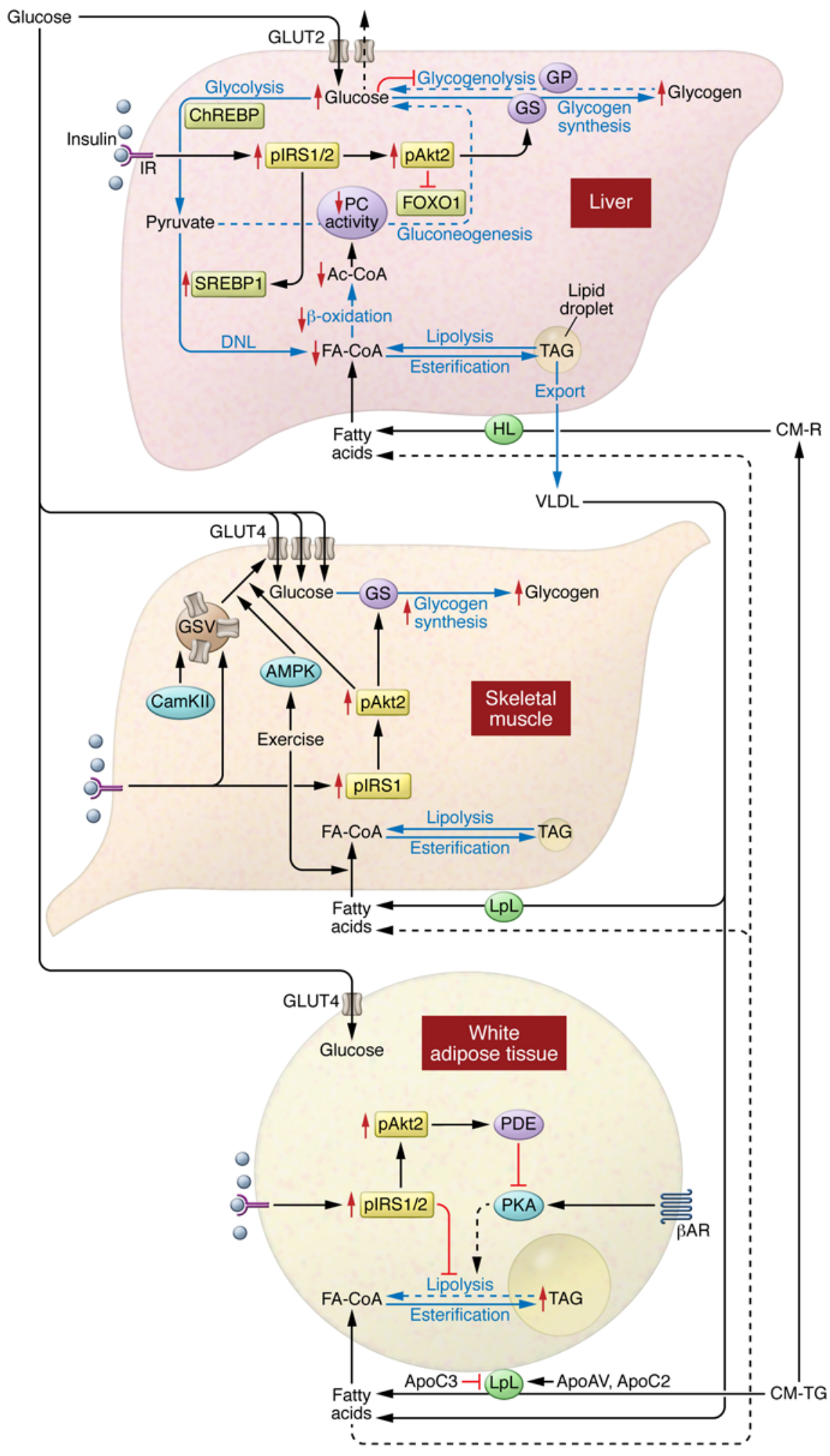

Figure 1. Insulin action promotes nutrient storage. In the liver, nutrient flux (blue arrows) is optimized by the coordinated action of hormonal and nutrient signals. Insulin signaling through Akt2 activates glycogen synthase and decreases the transcription of gluconeogenic enzymes via inactivation of FOXO1. Insulin signaling also promotes activation and expression of SREBP1. Glucose inhibits glycogenolysis and, when metabolized, can activate ChREBP. SREBP1 and ChREBP both promote DNL. Liver uptake of fatty acids (FAs) from chylomicron remnants or FAs that spill over from peripheral lipolysis also contributes to hepatic lipid synthesis via reesterification. In skeletal muscle, insulin activates the movement of CSVs to the plasma membrane, enhancing glucose uptake and glycogen synthesis. GSV translocation can also be activated by exercise. Skeletal muscle will also take up FAs for oxidation. In adipose tissue, insulin acts to inhibit lipolysis and promote glucose uptake. Adipose tissue is the primary storage location for lipids, with a coordinate uptake of fats from chylomicrons and very low-density lipoprotein (VLDL). $\beta A R, \beta$-adrenergic receptor; CM-TC, chylomicron-triglycergides; $\mathrm{IR}$, insulin receptor; $\mathrm{HL}$, hepatic lipase; CM-R, chylomicron remnants; CAM-KII, calmodulin kinase II; GS, glycogen synthase; GP; glycogen phosphorylase; Ac-Coa, Acetyl-CoA.

suppression of hepatic glucose production after meals $(12,13)$. In a canine study, raising portal insulin eight-fold - while keeping plasma glucose and glucagon concentrations fixed - lowered hepatic glucose production within 30 minutes but did not reduce protein expression of gluconeogenic enzymes. Two hours of sustained hyperinsulinemia were required to detect a modest decline in protein (14). More than 50 years ago, Levine and Fritz proposed that insulin inhibited hepatic glucose production through an indirect mechanism (15). Bergman and others postulated that insulin's ability to suppress hepatic glucose production was linked to the suppression of adipose lipolysis (16). Recent studies by Perry et al. provide a molecular mechanism linking insulin action in white adipose tissue (WAT) to the regulation of hepatic gluconeogenesis (Figure 3). First, insulin suppressed adipose lipolysis, lowered hepatic acetyl-CoA

phosphorylation of GSK3 appears dispensable for normal hepatic glucose metabolism (10). Thus, Akt activation is not a linchpin for coordinating hepatic glucose metabolism, and other pathways also regulate this process.

Insulin-mediated suppression of hepatic glucose production is often attributed to reduced transcription of gluconeogenic enzymes; however, this model fails to explain the rapid content (an allosteric activator of pyruvate carboxylase [PC]), and reduced PC activity and PC flux (17). Second, by inhibiting lipolysis, insulin curtailed glycerol delivery to the liver and reduced conversion of glycerol to glucose $(18,19)$. Hepatic insulin signaling may establish the transcriptional tone of gluconeogenic enzymes and determine the gluconeogenic capacity of the liver, but the ability of insulin to acutely regulate hepatic glu- 


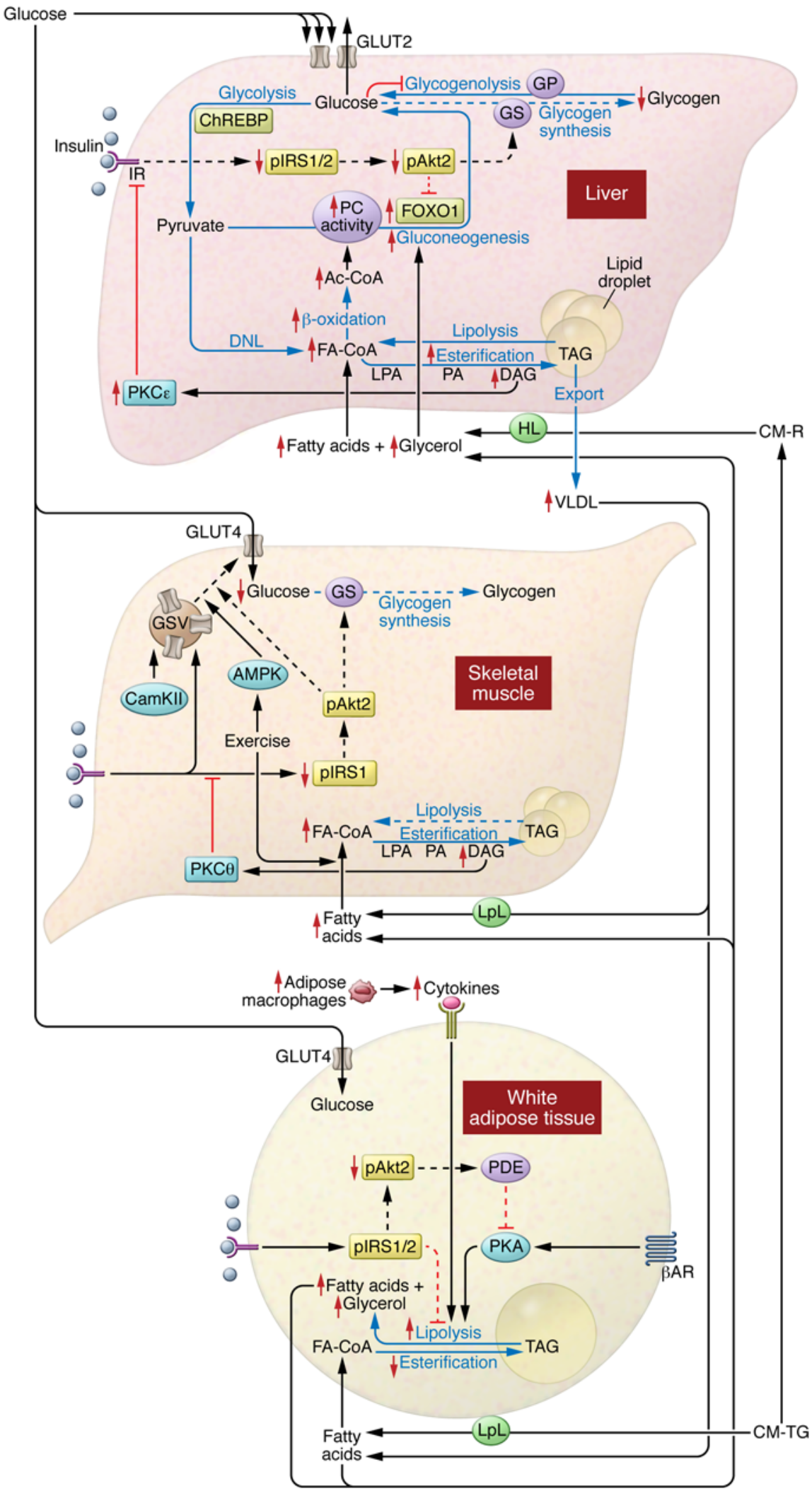

Figure 2. Mechanisms of insulin resistance. In the liver, DAG-mediated activation of PKC $\varepsilon$ impairs hepatic insulin signaling, constraining insulin-stimulated hepatic glycogen synthesis. Hepatic lipid synthesis continues unabated. In the skelatal muscle, DAG-mediated activation of PKC $\theta$ impairs muscle insulin signaling, impeding insulin-stimulated muscle glucose uptake and leading to increased glucose delivery to the liver. Exercise can still function to promote glucose uptake. In adipose tissue, cytokine release from ATMs promotes adipose lipolysis and leads to increased release of fatty acids (FAs). This will further drive hepatic lipid synthesis and activate hepatic gluconeogenesis via acetyl-CoA-mediated (Ac-CoA-mediated) activation of $P C$ and glycerol, increasing glucose production via substrate push. IR, insulin receptor; GP; glycogen phosphorylase; GS, glycogen synthase; LPA, lysophosphatidic acid; HL, hepatic lipase; CM-R, chylomicron remnants; VLDL, very low-density lipoprotein; CAM-KII, calmodulin kinase II; IRS1/2, insulin receptor substrate $1 / 2 ; \beta A R, \beta$-adrenergic receptor; CM-TG, chylomicron- triglycergides.

skeletal muscle activates Akt2 (Figure 1). Akt2 activation leads to phosphorylation and inactivation of two RabGTPases, Akt substrate of $160 \mathrm{kDa}$ (AS160, also known as TBC1D4; refs. 20, 21) and TBC1D1 (22), which increase glucose transporter type 4-containing (GLUT4containing) storage vesicles (GSVs) trafficking to the plasma membrane, cellular glucose transport, and glycogen synthesis. Some recent studies also suggest the presence of a PI3K-independent arm that can promote cleavage of tether containing UBX domain for GLUT4 (TUG), a protein that sequesters GSVs in a perinuclear storage compartment (23-26). Insulin-independent mechanisms also activate muscle glucose uptake. Mice with targeted deletion of the insulin receptor in skeletal muscle have impaired insulininduced muscle glucose uptake (27) but have normal exercise-induced muscle glucose uptake (28). Muscle contraction activates AMPK, which phosphorylates proteins that regulate GSV translocation (29). AMPK activation is one of many factors that comprise a network of signals that promote glucose uptake in response to exercise but independently of insulin action (recently reviewed in ref. 30).

coneogenesis occurs mostly by an indirect mechanism through inhibition of WAT lipolysis.

Muscle glycogen synthesis accounts for the majority of postprandial glucose disposal (14). As in the liver, insulin action in the
WAT glucose uptake is largely insulin dependent and regulated by pathways similar to those in skeletal muscle (Figure 1). WAT glucose uptake, quantitatively, is relatively minor, accounting for only $5 \%-10 \%$ of whole body glucose uptake (31, 


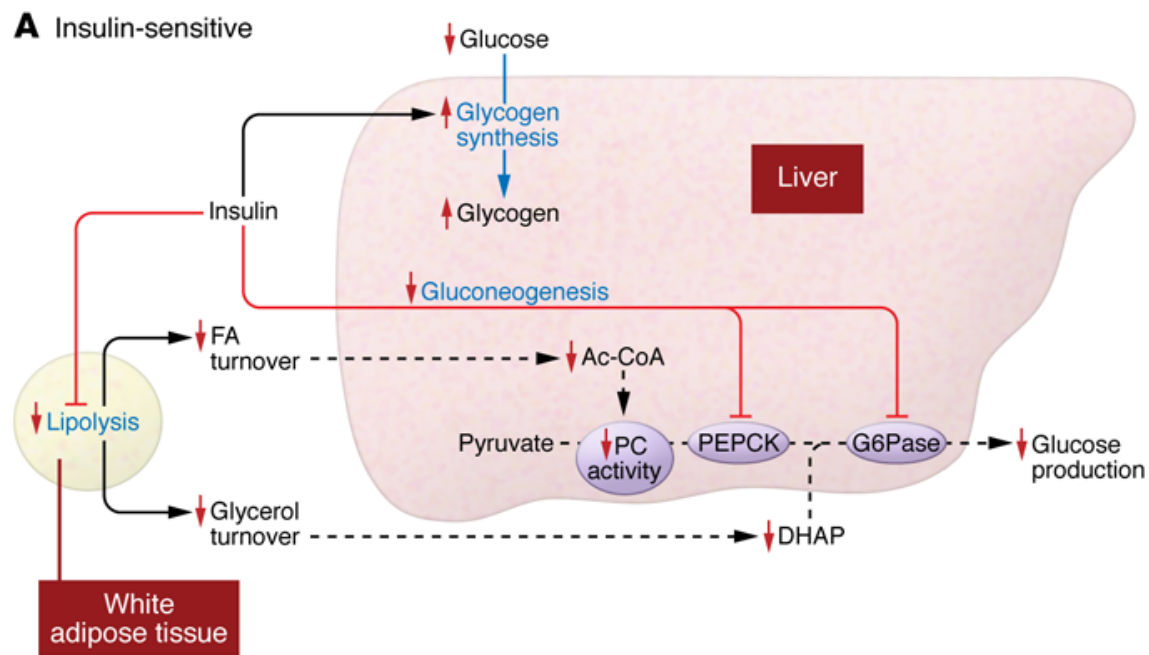

B Insulin resistance/type 2 diabetes

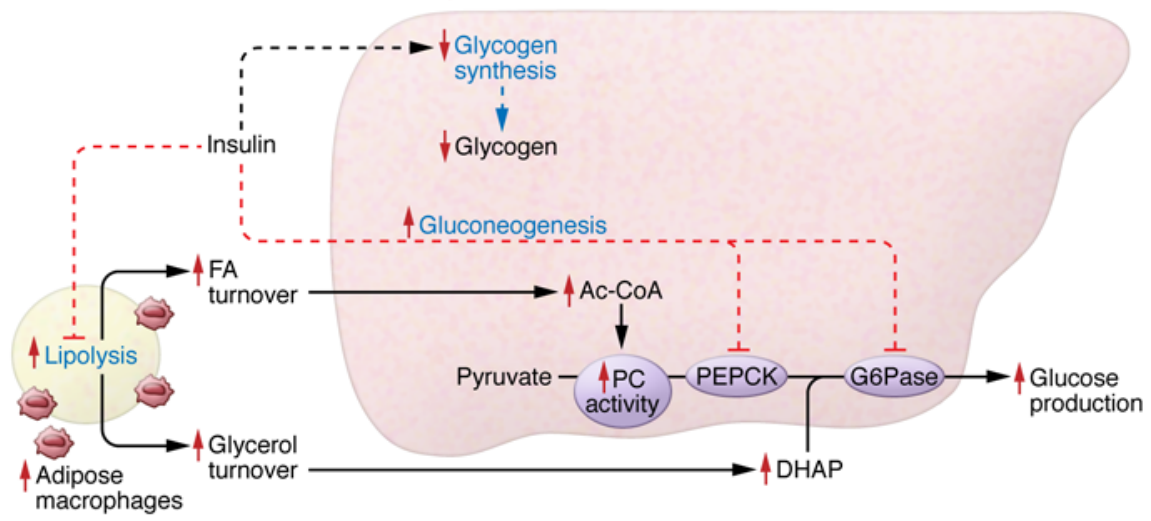

Figure 3. Insulin regulates hepatic glucose metabolism directly via hepatic insulin action and indirectly via adipose insulin action. (A) Insulin regulates hepatic glucose metabolism through both a direct mechanism and an indirect mechanism. The direct mechanism is mediated through activation of hepatocyte insulin receptors, which decreases hepatic glucose production acutely by activating hepatic glycogen synthesis and chronically through transcriptional downregulation of gluconeogenic enzymes, predominately by FOXO1 phosphorylation. Insulin also suppresses hepatic glucose metabolism by an indirect mechanism mediated by insulin action on WAT. Insulin inhibition of lipolysis suppresses fatty acid and glycerol turnover. This decreases fatty acid (FA) delivery to the liver, leading to reductions in hepatic acetyl-CoA (Ac-CoA) content, which in turn leads to allosteric reductions in hepatic PC activity and flux. Additionally, insulin suppression of lipolysis decreases glycerol delivery to liver and decreases conversion of glycerol to glucose. PEPCK, phosphoenolpyruvate carboxykinase; G6Pase, glucose 6-phosphatase. (B) In T2D, dysregulation of hepatic and adipose insulin action both contribute to hyperglycemia. Impaired hepatic insulin signaling, mediated by DAG/PKC $\varepsilon$ inhibition of insulin receptor kinase activity, results in reduced insulin activation of hepatic glycogen synthesis and postprandial hyperglycemia. Adipose tissue inflammation and adipose insulin resistance results in increased rates of lipolysis and increased rates of FA and glycerol delivery to the liver. Increased FA delivery to the liver increases hepatic Ac-CoA content, leading to allosteric activation of PC activity and PC flux that increases hepatic gluconeogenesis. Additionally, increased glycerol delivery to the liver further increases hepatic gluconeogenesis through a substrate push mechanism. Dotted lines represent decreased action or flux. DHAP, dihydroxyacetone phosphate.

32). Thus, while glucose can be taken up by WAT, these tissues likely do not have a major quantitative role in postprandial glucose metabolism.

Lipids are a second major fuel source. Dietary lipids predominantly enter the systemic circulation as apolipoprotein
B48-containing (ApoB48-containing) triglyceride-rich chylomicrons that are rapidly cleared. The hydrolysis of triglyceride into fatty acids by lipoprotein lipase (LpL, Figure 1) is a rate-controlling step for cellular lipid uptake from plasma and is highly regulated (recently reviewed in ref. 33). The release of triglyceride from intracellular stores is similarly highly controlled by intracellular lipases (reviewed in ref. 34). While a full discussion of the uptake and release of lipids is beyond the scope of the present review, we review some studies to illustrate how the regulation of LpL activity fits into the broader coordination of energy metabolism. For example, insulin increases expression of LpL in s.c. adipose tissues (35), while insulin resistance in humans is associated with a decrease in s.c. adipose LpL expression $(36,37)$. Whereas insulin regulates basal LpL expression, a number of other proteins regulate LpL activity (38). As one example, when exercising muscle is compared with nonexercising muscle (e.g., single-leg cycling), there is a PPAR $\delta$-regulated induction of angiopoietin like-4 (ANGPLT4, an inhibitor of LpL) in the nonexercising muscle matched with a concurrent AMPK-mediated suppression of ANGPLT4 in the exercising muscle (39). Thus, coordination of LpL activity channels lipids to metabolically active sites.

\section{Ectopic lipid accumulation and insulin resistance}

The association between obesity, insulin resistance, and T2D has long been appreciated. ${ }^{1} \mathrm{H}$ MRS studies have demonstrated that intramyocellular lipid (IMCL) content is a much better predictor of muscle insulin resistance than fat mass in healthy, young, sedentary, lean individuals (40) and nonobese, nondiabetic but insulinresistant adults (41) and children (42), suggesting a potential causal role for IMCL mediator(s) in this process.

Over a half century ago, Randle and colleagues concluded that muscle insulin resistance associated with obesity could be attributed to increased fatty acid oxidation that limits insulin-stimulated glucose utilization (43). The essential tenet of this model was that increased delivery and oxidation of fatty acids leads to accumulation of citrate that inhibits phosphofructokinase, a key enzyme in glycolysis, leading to increases in intramyocellular glucose-6-phosphate and glucose, which thereby impairs glucose utilization (43). 
Yet, noninvasive measurements of these metabolites by ${ }^{13} \mathrm{C}$ and ${ }^{31} \mathrm{P}$ MRS studies found that the intramyocellular concentrations of these metabolites were decreased in human muscle during the acute induction of insulin resistance by a lipid infusion, demonstrating that fatty acids impair insulin-stimulated glucose metabolism in muscle by blocking glucose transport into the cell, not through inhibition of glycolysis $(44,45)$. Similar reductions in glucose transport were observed in insulin-resistant, obese individuals (46); patients with T2D (47); and lean, normoglycemic but insulin-resistant offspring of T2D parents (48). Taken together, these data support the hypothesis that an IMCL metabolite induces insulin resistance by causing defects in insulinstimulated muscle glucose transport activity (45).

IMCL accumulates when there is a mismatch between lipid oxidation and lipid delivery to the myocyte (Figure 2 and refs. $48,49)$. In elderly subjects, skeletal muscle insulin resistance was associated with increased IMCL and a $35 \%$ reduction in both mitochondrial oxidative and phosphorylation activity. Ageassociated reductions in mitochondrial function may be due to cumulative damage from ROS (50). Supporting this hypothesis, transgenic mice that overexpress a mitochondrial-targeted form of human catalase were protected from mitochondrial oxidative damage associated with aging and were able to maintain normal muscle mitochondrial function, muscle triglyceride/diacylglycerol (DAG) content and insulin action (51). Muscle mitochondrial oxidative and phosphorylation activity were also reduced by approximately $40 \%$ in healthy, young, lean, insulin-resistant offspring of patients with T2DM $(52,53)$. In contrast to aging, these reductions in mitochondrial activity appear to be secondary to reduction in mitochondrial density (54) and may be due in part to diminished expression of LpL in skeletal muscle, which could limit PPAR $\delta$-mediated mitochondrial biogenesis (55). Together, these studies demonstrate the close association between ectopic lipid accumulation and insulin resistance in skeletal muscle, and they highlight the potential role of reduced mitochondrial function in promoting IMCL accumulation.

\section{Cellular mechanisms of muscle insulin resistance}

IMCL primarily reflects intramyocellular triglyceride content. While IMCL strongly correlates with muscle insulin resistance in sedentary individuals, triglycerides themselves have been disassociated from insulin resistance, suggesting that other lipid species (e.g., DAGs, ceramides, etc.) mediate insulin resistance (56). Numerous studies have delineated the mechanistic links between DAG accumulation and muscle insulin resistance and point specifically to a proximal defect in insulin signaling. Insulin-stimulated tyrosine phosphorylation of IRS-1 and IRS-1-associated PI3K activation were acutely impaired in skeletal muscle of lipid-infused humans $(45)$ and rodents $(56,57)$. In rodents, lipid infusion and high-fat feeding led to transient increases in muscle DAG content (56), resulting in sustained activation of PKC $\theta$ that limited phosphorylation of IRS-1 by IRTK (Figure 2). Lipid infusions in healthy human volunteers similarly increased skeletal muscle DAG and nPKC activation (PKC $\delta$, ref. 58; PKC $\theta$, ref. 59) and caused muscle insulin resistance. These studies support a mechanistic model in which muscle DAG accumulation activates PKC $\theta$, which impairs insulin signaling.
The development of muscle insulin resistance can lead to metabolic disease. This has been observed in genetic mouse models of selective muscle insulin resistance due to muscle-specific deletions of the IRTK (27) and GLUT4 (60), which are prone to hepatic steatosis (61) and increased adiposity (27). In young, lean, otherwise healthy humans with skeletal muscle insulin resistance, ingested glucose is not taken up by muscle and instead gets diverted to the liver, where it becomes substrate for hepatic de novo lipogenesis (DNL), increasing liver triglyceride synthesis and plasma triglyceride concentrations, and reducing plasma HDL concentrations (ref. 62 and Figure 4).

\section{Cellular mechanisms of hepatic insulin resistance}

NAFLD is strongly associated with hepatic insulin resistance. Though different models have been proposed for the development of hepatic insulin resistance (reviewed in ref. 5), a substantial body of work also supports the role of DAG accumulation and PKC $\varepsilon$ activation in impairing hepatic insulin action. Briefly, studies in patients with generalized lipodystrophy demonstrated that ectopic lipid accumulation in liver and skeletal muscle was associated with severe hepatic and muscle insulin resistance, despite the absence of adipose tissue (63). Leptin therapy reduced calorie intake, resolved hepatic steatosis, and improved insulin action (63). Lipodystrophic mice have a similar phenotype, and fat transplantation rescued these mice by allowing a redistribution of lipids from ectopic sites to transplanted adipose tissue and normalization of insulin action (64). Similarly, mice overexpressing $\mathrm{LpL}$ in the liver develop hepatic steatosis and liver-specific insulin resistance (65). In rats and mice, short-term, high-fat diets lead to hepatic steatosis and hepatic insulin resistance without muscle lipid accumulation or peripheral insulin resistance. Thus, these studies demonstrate that ectopic lipid in the liver is specifically associated with hepatic insulin resistance and disassociate hepatic insulin resistance from obesity and visceral adiposity.

In fat-fed rats, the increase in hepatic DAG content activates $\mathrm{PKC} \varepsilon$, the primary $\mathrm{PKC}$ isoform in liver $(66,67)$. These changes are associated with decreased activation of IRTK (ref. 68 and Figure 2). Lowering PKCe expression protected rats from lipid-induced hepatic insulin resistance and preserved IRTK activity, though hepatic DAG and triglyceride content was unchanged (68). Similarly, $\mathrm{Prkce}^{-/-}$mice are protected from diet-induced insulin resistance following one week of high-fat feeding, despite increases in liver lipid content (69). These data support a model for hepatic insulin resistance where the accumulation of hepatic DAG activates PKC $\varepsilon$ and impairs IRTK activation, and demonstrate that $\mathrm{PKC} \varepsilon$ activation is necessary for lipid-induced hepatic insulin resistance.

This paradigm has been translated to humans. Kumashiro et al. studied determinants of insulin resistance in a cohort of patients undergoing bariatric surgery (70). Hepatic DAG content and $\mathrm{PKC} \varepsilon$ activation were the strongest predictors of insulin sensitivity. In contrast, there was no association between insulin sensitivity and other factors implicated in the pathogenesis of hepatic insulin resistance (e.g., JNK1 activation, ceramide content, etc.). Magkos et al. also demonstrated that hepatic DAG content (but not hepatic ceramide content) was the best predictor of hepatic insulin resistance in obese humans (71). 


\section{A Normal: insulin-sensitive}

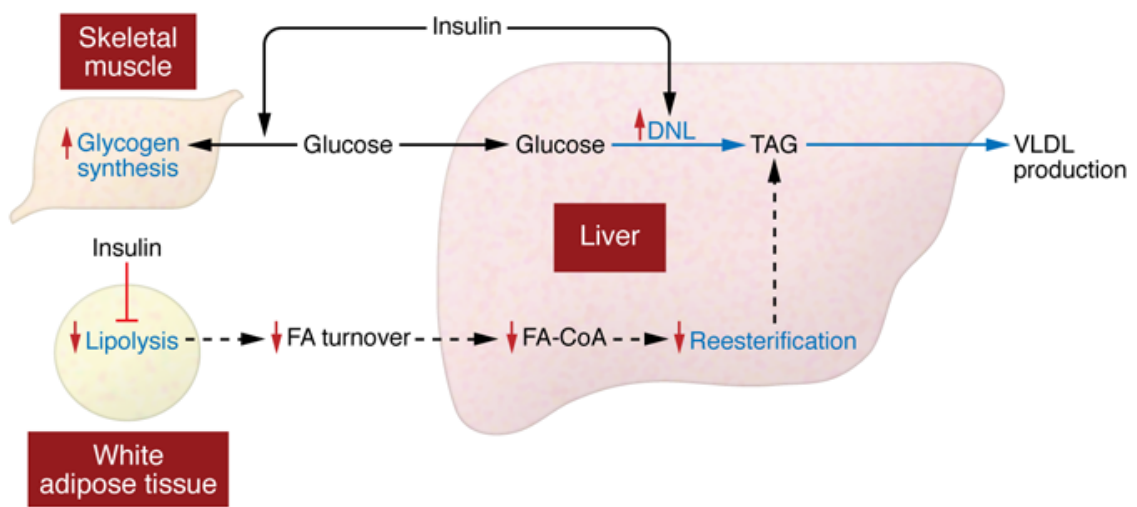

B Prediabetes: selective muscle insulin resistance

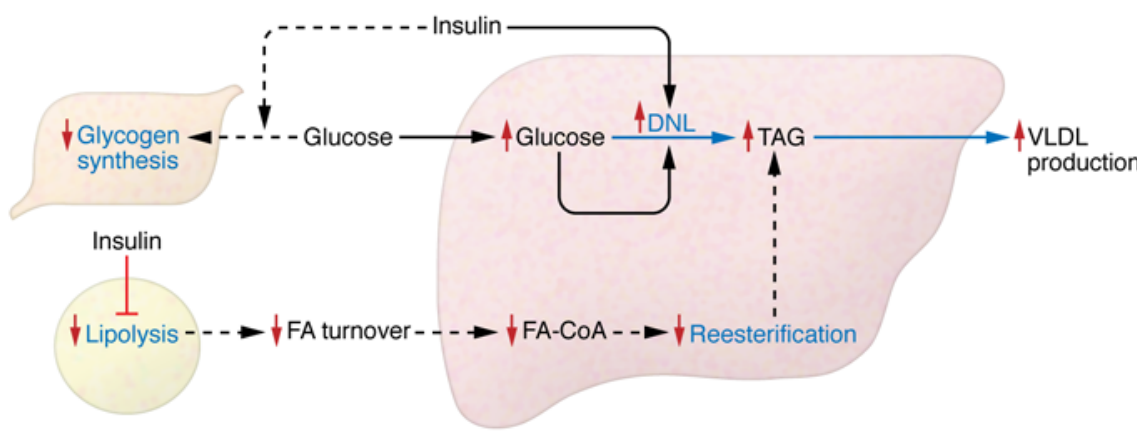

Type 2 diabetes: liver, muscle, and adipose insulin resistance

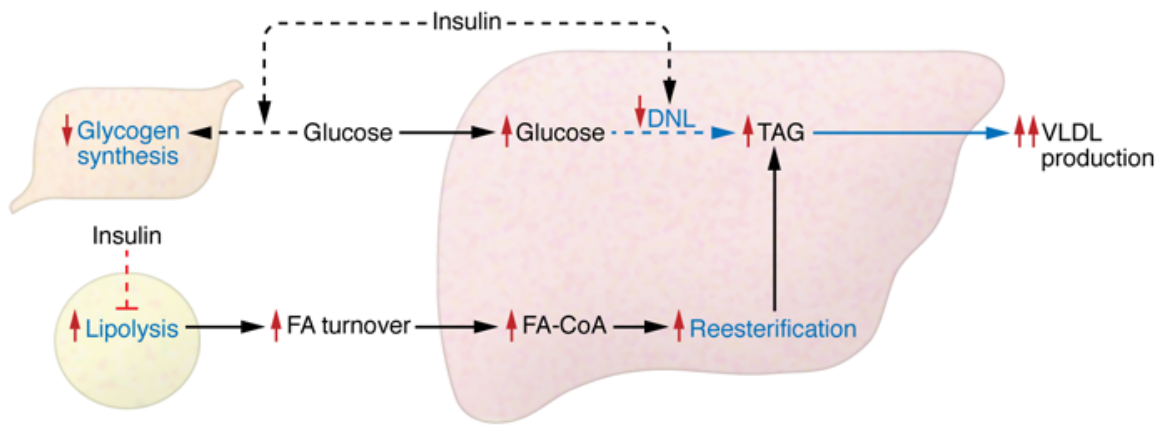

Figure 4. Insulin regulates hepatic lipid metabolism directly via hepatic insulin signaling and indirectly via adipose and muscle insulin action. (A) Muscle insulin action promotes postprandial muscle glucose uptake, and adipose insulin action decreases hepatic fatty acid (FA) delivery and reesterification of hepatic FAs into triglycerides. Direct hepatic insulin action will activate de novo lipogenesis and conversion of excess carbohydrate substrate into triglyceride and will promote export of hepatic triglyceride to adipose tissue as very low-density lipoprotein (VLDL). DNL, de novo lipogenesis. (B) Selective muscle insulin resistance in the prediabetic state, due to selective ectopic IMCL accumulation and DAG/ PKC $\theta$-mediated inhibition of muscle insulin signaling, leads to decreased insulin-stimulated glucose transport activity. This diverts ingested glucose to the liver, where the combination of postprandial hyperinsulinemia and hyperglycemia stimulates hepatic de novo lipogenesis, resulting in increased VLDL production, hypertriglyceridemia, and reductions in plasma HDL. (C) With the progression to hepatic steatosis and impaired insulin signaling in all key insulinresponsive tissues (liver, skeletal muscle, and adipose tissue), rates of adipose tissue lipolysis are increased, resulting in increased FA delivery to liver, which results in increased hepatic esterification of fatty acids to triglyceride. This process is regulated predominately by a substrate push mechanism and is independent of insulin signaling in the hepatocyte. In contrast, hepatic de novo lipogenesis, which is dependent on hepatic insulin signaling, is reduced. Dotted lines represent decreased action or decreased flux.
There are some circumstances in which hepatic steatosis appears disassociated from hepatic insulin resistance. Decreasing expression of comparative gene identification-58 (CGI-58), an activator of adipose triglyceride lipase (ATGL), led to marked hepatic steatosis and an increase in total DAG content without hepatic insulin resistance (72). However, loss of CGI-58 altered the subcellular distribution of DAG and PKC $\varepsilon$; specifically, CGI-58 knockdown prevented DAG accumulation at the plasma membrane, PKC $\varepsilon$ activation, and the associated impairments in hepatic insulin action (73).

A common single nucleotide polymorphism (rs738409, I48M) in the lipid droplet protein patatin-like phospholipase domaincontaining protein 3 (PNPLA3, also called adiponutrin) has been associated with increased hepatic steatosis but not insulin resistance (74). Mice expressing the knock-in mutation develop dietinduced steatosis with normal glucose tolerance (75). This mutation may increase PNPLA3 content on lipid droplets (75) and lead to an increase in triglyceride content, but not other bioactive lipids (i.e., DAG; ref. 76). Thus, instances of apparent disassociation of hepatic steatosis and hepatic insulin resistance may be explained by a better understanding of the subcellular distribution of DAG and nPKCs.

Finally, loss of insulin-mediated Akt activation may not be an absolute requisite for insulin resistance. Coate and colleagues demonstrated that dogs fed a high-fat diet or high-fructose diet for four weeks developed a similar degree of insulin resistance (77). High-fat feeding impaired insulin-stimulated Akt phosphorylation, but a high-fructose diet did not. Instead, high-fructose feeding impaired glucokinase activity and glycogen synthesis. Thus, the typical high-calorie diets consumed by humans may impede hepatic insulin action via multiple pathways.

Ceramides are also bioactive lipid molecules that are implicated in the development of insulin resistance. Increases in hepatic and muscle ceramide content have been associated with insulin 
resistance in rodents (78), and inhibitors of ceramide synthesis can prevent insulin resistance $(79,80)$. However, a disassociation between ceramide content and tissue insulin resistance has been reported in multiple studies $(70,71,81)$, and the underlying mechanism linking ceramides to insulin resistance has not been fully resolved. Recently, two studies examined how a specific ceramide species, C16:0, impedes mitochondrial function, allowing triglyceride accumulation and insulin resistance $(82,83)$. Though not examined in these studies, it is possible that the reciprocal relationship between C16:0 ceramide and mitochondrial oxidation could also increase DAG, activate nPKCs, and impair insulin signaling.

\section{Adipose insulin resistance}

In part, adipose insulin resistance is the inability of insulin to activate adipose glucose transport, promote lipid uptake, and suppress lipolysis (Figure 3). While decreased adipose glucose uptake is demonstrated in both in vivo and in vitro models, the mechanism and metabolic impact of impaired insulin-mediated glucose uptake in adipose tissue is unclear. Insulin-stimulated adipose glucose metabolism is quantitatively minor compared with whole body insulin-stimulated glucose metabolism; however, glucose metabolism within adipocytes exerts extra-adipose actions. For example, loss of adipose GLUT4 in mice does not alter adiposity or weight gain but leads to insulin resistance in skeletal muscle and liver (84). Glucose entry into adipose cells activates carbohydrate response element binding protein (ChREBP), which may impact adipose lipid metabolism (85). Intriguingly, adipose ChREBP expression appears directly related to insulin sensitivity in humans (85). Adipocytes release specific fatty acids that are associated with increased insulin sensitivity, like palmitoleate $(86,87)$ or monomethyl branched chain fatty acids (88). Recently, ChREBP was implicated in the synthesis of fatty acid esters of hydroxy fatty acids (FAHFAs), which improve glucose tolerance (89). Adipocytokines (e.g., leptin, resistin, and adiponectin) also impact systemic insulin sensitivity (90). Increases in leptin and resistin are associated with insulin resistance, while adiponectin is associated with increased insulin sensitivity. Mice lacking adiponectin are prone to hepatic steatosis and hepatic insulin resistance (91, 92). While overexpression of adiponectin in $o b / o b$ mice leads to increased adiposity, the improvement in adipose function lowered adipose inflammation, circulating lipids, and hepatic DAG content and improved hepatic insulin action (93). Thus, WAT exerts systemic effect via the release of substrates (fatty acids, glycerol) and signaling molecules (adipokines and lipokines).

Common genetic mutations impact ectopic lipid storage. Recently, polymorphisms in APOC3 were shown to predispose lean, male individuals to NAFLD and insulin resistance $(94,95)$. These polymorphisms led to approximately $30 \%$ higher plasma ApoC3 concentrations and postprandial hypertriglyceridemia through ApoC3's inhibitory effect on LpL activity, which increased hepatic uptake of chylomicron remnants. Similarly, transgenic mice that overexpress human ApoC3 in the liver had increased hepatic triacylglycerol (TAG)/DAG accumulation when fed a high-fat diet with the activation of hepatic PKC $\varepsilon$ and the development of hepatic insulin resistance (89).

Multiple factors impede the ability of insulin to suppress adipose lipolysis, including inflammation. Activated adipose tissue macrophages (ATMs) are recruited via chemokine signaling (96, 97) and release cytokines that promote lipolysis. TNF $\alpha$ lowers perilipin expression, presumably enhancing lipolysis $(98,99)$. Additionally, TNF $\alpha$, IL-1 $\beta$, and IFN $\gamma$ decrease expression of fat-specific protein 27 (FSP27) (100), which may stabilize lipid droplets by controlling lipase access to triglycerides. Adipose lipolysis is also regulated by other pathways. Some data suggest that hypothalamic insulin may suppress sympathetic nervous system signaling and thereby reduces catecholamine-mediated lipolysis (101-103). Leptin may also regulate WAT lipolysis via the hypothalamicpituitary-adrenal (HPA) axis (12). Leptin clearly has pleiotropic effects on glucose metabolism, including reduction in food intake, which reduces ectopic lipid accumulation and improves hepatic and muscle insulin action in lipodystrophic individuals (63); reduction of glucagon secretion (104); neural regulation of hepatic glucose production (105); and regulation of glucocorticoid secretion $(18,106)$. Perry et al. demonstrated the latter, specifically that leptin treatment rescued streptozotocin-treated rats with ketoacidosis by suppressing adrenocorticotropic hormone-driven adrenal corticosterone production. Despite the near total absence of insulin, leptin normalized fasting rates of WAT lipolysis, decreased hepatic acetyl-CoA and PC flux, and lowered fasting rates of hepatic gluconeogenesis and ketogenesis (18). It bears noting that adipocytes are exquisitely sensitive to insulin and even low concentrations will trump the effect of hypercorticosteronemia (107). Insulin deficiency may also suppress adipose LpL expression (108), which could further compound the hypertriglyceridemia seen in diabetic states. Consistent with this hypothesis, mice overexpressing skeletal muscle LpL were protected from the hypertriglyceridemia seen with streptozotocin treatment, demonstrating that the creation of a tissue depot for lipids could alter lipid storage and prevent hyperlipidemia (108).

\section{Regulation of hepatic triglyceride synthesis and selective hepatic insulin resistance}

A central paradox in the pathogenesis of T2D is the apparent selective nature of hepatic insulin resistance wherein insulin fails to suppress hepatic glucose production, yet continues to stimulate lipogenesis, resulting in hyperglycemia, hyperlipidemia, and hepatic steatosis. Efforts to explain this paradox have focused on finding a branch point in insulin signaling where hepatic glucose and lipid metabolism diverge. Vatner et al. hypothesized that hepatic triglyceride synthesis could be driven by substrate (fatty acids), independent of changes in hepatic insulin signaling (109). They tested this in awake normal rats, high-fat-fed, insulin-resistant rats and insulin receptor 2'-O-methoxyethyl chimeric antisense oligonucleotide-treated rats infused with varying concentrations of lipid and insulin. Rates of fatty acid esterification into hepatic triglyceride were found to be dependent on the rate of fatty acid delivery to the liver and independent of hepatocellular insulin signaling. In contrast, de novo hepatic lipogenesis was insulin dependent and was reduced in rats with defective hepatic insulin signaling. These studies offer a solution to this paradox. The major source of hepatic lipid synthesis, esterification of preformed fatty acids, is primarily dependent on substrate delivery and largely independent of hepatic insulin action (Figure 4). 
Monosaccharides act as both substrates for and nutrient regulators of hepatic DNL. In normal subjects, glucose is largely metabolized in skeletal muscle. However, muscle insulin resistance, which occurs early in the course of T2D (47), increases glucose delivery to the liver, where the lipogenic machinery has been primed by chronic hyperinsulinemia (110). Fructose, which is consumed in nearly equal amounts as glucose, can also promote lipogenesis. Both glucose and fructose may also act to regulate hepatic lipogenesis independently of insulin action (Figure 1). Both increase SREBP1c expression even in the absence of insulin (111), though insulin action may be necessary for full SREBP1c processing to realize the maximal conversion of these sugars into lipids (112). But fructose, unlike glucose, is primarily funneled into the liver, providing a substantial carbon substrate for lipogenesis. Human subjects who consumed fructose-containing beverages, in comparison with those consuming isocaloric glucose-containing beverages, developed hyperlipidemia and insulin resistance despite gaining a similar amount of weight (113). Monosaccharides also enlist other transcription factors, including ChREBP $(114,115)$, PPAR $\gamma$ coactivator 1- $\beta$ (116), and liver $X$ receptor (117), to activate lipogenesis. In summary, though insulin potentiates DNL by activating SREBP1c, substrate flux into the liver also impacts hepatic lipid synthesis. Fatty acid flux promotes hepatic lipid synthesis by reesterification, while monosaccharide flux provides both the substrate and the stimulus for lipogenesis. Together, these alternate pathways may promote hepatic lipid synthesis despite the presence of hepatic insulin resistance.

Increased WAT lipolysis also promotes hepatic insulin resistance by increasing hepatic gluconeogenesis. First, lipolysis increases fatty acid delivery to the liver, leading to increased hepatic acetyl-CoA content, which activates PC activity and PC flux $(17,18)$. Second, WAT lipolysis also increases glycerol delivery to the liver which can promote glucose production by a substrate dependent push mechanism independently of hepatic insulin action (17-19). Both of these processes are independent of insulin signaling in the liver and are dependent on normal insulin signaling in the adipocyte. Inhibiting lipolysis with an ATGL inhibitor lowered rates of hepatic gluconeogenesis in normal chow-fed rats, insulin-resistant high-fat-fed rats, and insulin-resistant rats treated with an antisense oligonucleotide to knock down hepatic and adipocyte IRTK. The importance of intrahepatic DAG and acetyl-CoA in promoting hepatic insulin resistance and increased hepatic gluconeogenesis was also demonstrated in rats treated with either a liver-targeted or controlled release formulation of a mitochondrial protonophore $(81,118)$. In both cases, subtle increases in hepatic mitochondrial inefficiency reduced hepatic DAG and acetyl-CoA content with marked improvement in hepatic insulin signaling and reductions in rates of hepatic gluconeogenesis and fasting hyperglycemia in diabetic animals. These studies inform a model that recognizes a plurality in insulin's regulation of hepatic glucose and lipid metabolism. Insulin acts directly via hepatic insulin signaling to stimulate net hepatic glycogen synthesis and hepatic DNL, but insulin's extrahepatic action to suppress lipolysis in WAT is critical for maintaining normal carbohydrate and lipid metabolism by inhibiting hepatic gluconeogenesis and curtailing hepatic esterification of fatty acids to triglyceride.

\section{Decreasing ectopic lipid accumulation reverses insulin resistance and $\mathrm{T} 2 \mathrm{D}$}

Weight loss addresses the root causes of insulin resistance and is an essential goal for all patients with ectopic lipid deposition, insulin resistance, and T2D. Modest weight loss can reduce hepatic lipid content, normalize hepatic insulin sensitivity (119), and "reverse" T2D (119, 120). Aerobic exercise also improves insulin sensitivity. Skeletal muscle glucose transport is activated by insulin-independent mechanisms in response to exercise and aerobic conditioning. Exercise is a potent therapy for patients with T2D, as it bypasses the block in insulin signaling to enhance muscle glucose uptake and potentially reestablish the normal disposal of dietary glucose into muscle glycogen. In insulin-resistant subjects, a single session of aerobic exercise augmented muscle glucose transport activity and insulin-stimulated muscle glycogen synthesis (48). Even short (6-minute) bursts of exercise prior to meals can significantly improve the diurnal glucose excursion (121). Further evidence in support of the key role of substrate in promoting increased hepatic DNL was demonstrated by a study that found that a single bout of elliptical training resulted in increased postprandial muscle glycogen synthesis and reduced hepatic DNL without altering plasma insulin concentrations in healthy, young, lean individuals with selective muscle insulin resistance (122).

\section{Conclusions}

Calorie imbalance, promoted by our modern, toxic environment, results in ectopic lipid accumulation in liver and skeletal muscle, which impedes insulin action in these tissues. Subsequent adipocyte dysfunction promotes macrophage infiltration and increases lipolysis, further impairing hepatic carbohydrate and lipid metabolism in several ways. First, increased fatty acid flux promotes fatty acid esterification and hepatic triglyceride synthesis, exacerbating hepatic steatosis, hepatic insulin resistance, and hypertriglyceridemia (Figure 4). Fatty acid delivery also increases hepatic acetyl-CoA, which allosterically activates PC, while the increased delivery of glycerol further increases hepatic gluconeogenesis (Figure 3). These hepatic processes are all mostly substrate driven and independent of insulin signaling in the liver but dependent on insulin signaling in WAT. In contrast, hepatic glycogen synthesis and hepatic DNL are dependent on both substrate (glucose and fructose) delivery to liver and the direct effects of insulin signaling in liver and are reduced with hepatic insulin resistance and insulin deficiency. While increased $\beta$ cell function and hyperinsulinemia initially try to compensate for these dysregulated processes, glucolipotoxicity and genetic factors lead to $\beta$ cell failure and progression to T2D.

Our understanding of the molecular basis of insulin resistance and increased hepatic gluconeogenesis will inform our approach to the global diabetes epidemic. Policies and education that encourage better nutrition and minimize sedentary behavior will promote default behaviors that could lower the prevalence of T2D (123). But new drugs are also required. In this regard, FGF-21 has been shown to be effective in reducing hepatic steatosis and reversing insulin resistance in rodents (124) and is now in clinical trials (125). Acetyl-CoA carboxylase inhibitors decrease hepatic lipogenesis, increase fatty acid oxidation, and show promise in reversing fatty liver in rodent models of NAFLD and T2D 
(126-128). Proof-of-concept studies in rodent models of NALFD and T2D demonstrate that mildly increasing hepatic mitochondrial inefficiency can safely reverse hypertriglyceridemia, ectopic lipid-induced (DAG/nPKC) liver and muscle insulin resistance, steatohepatitis, liver fibrosis, and diabetes, offering a novel therapeutic target for T2D and nonalcoholic steatohepatitis (NASH) $(81,118,129)$. This knowledge and understanding gained over the past several decades into the pathogenesis of insulin resistance may avert the looming epidemics of diabetes and NAFLD/NASH and ensure a healthier future for subsequent generations (130).

\section{Acknowledgments}

Supported by grants from the NIH (DK-40936, DK-49230, DK-085638, DK-059635, and DK-45735) and Veterans Administration (I01 BX000901).

Address correspondence to: Varman T. Samuel or Gerald I. Shulman, Yale University School of Medicine, PO Box 208020, New Haven, Connecticut 06520, USA. Phone: (203) 937-3848. E-mail: varman.samuel@yale.edu (V.T. Samuel) or gerald.shulman@ yale.edu (G.I. Shulman).
1. Petersen KF, Laurent D, Rothman DL, Cline GW, Shulman GI. Mechanism by which glucose and insulin inhibit net hepatic glycogenolysis in humans. J Clin Invest. 1998;101(6):1203-1209.

2. Hwang JH, et al. Impaired net hepatic glycogen synthesis in insulin-dependent diabetic subjects during mixed meal ingestion. A 13C nuclear magnetic resonance spectroscopy study. JClin Invest. 1995;95(2):783-787.

3. Kasvinsky PJ, Shechosky S, Fletterick RJ. Synergistic regulation of phosphorylase a by glucose and caffeine. J Biol Chem. 1978;253(24):9102-9106.

4. Petersen KF, Laurent D, Yu C, Cline GW, Shulman GI. Stimulating effects of low-dose fructose on insulin-stimulated hepatic glycogen synthesis in humans. Diabetes. 2001;50(6):1263-1268.

5. Samuel Varman T, Shulman Gerald I. Mechanisms for insulin resistance: common threads and missing links. Cell. 2012;148(5):852-871.

6. Guertin DA, Sabatini DM. Defining the role of mTOR in cancer. Cancer Cell. 2007;12(1):9-22.

7. Alessi DR, et al. Characterization of a 3-phosphoinositide-dependent protein kinase which phosphorylates and activates protein kinase B $\alpha$. Curr Biol. 1997;7(4):261-269.

8. Stephens L, et al. Protein kinase B kinases that mediate phosphatidylinositol 3,4,5-trisphosphatedependent activation of protein kinase B. Science. 1998;279(5351):710-714.

9. Matveyenko AV, et al. Pulsatile portal vein insulin delivery enhances hepatic insulin action and signaling. Diabetes. 2012;61(9):2269-2279.

10. Wan M, et al. A noncanonical, GSK3-independent pathway controls postprandial hepatic glycogen deposition. Cell Metab. 2013;18(1):99-105.

11. Lu M, et al. Insulin regulates liver metabolism in vivo in the absence of hepatic Akt and Foxo1. Nat Med. 2012;18(3):388-395.

12. Ferrannini E, et al. The disposal of an oral glucose load in healthy subjects. A quantitative study. Diabetes. 1985;34(6):580-588.

13. Radziuk J, McDonald TJ, Rubenstein D, Dupre J. Initial splanchnic extraction of ingested glucose in normal man. Metabolism. 1978;27(6):657-669.

14. Ramnanan CJ, et al. Molecular characterization of insulin-mediated suppression of hepatic glucose production in vivo. Diabetes. 2010;59(6):1302-1311.

15. Levine R, Fritz IB. The relation of insulin to liver metabolism. Diabetes. 1956;5(3):209-219.

16. Rebrin K, Steil GM, Mittelman SD, Bergman RN. Causal linkage between insulin suppression of lipolysis and suppression of liver glucose output in dogs. J Clin Invest. 1996;98(3):741-749.
17. Perry RJ, et al. Hepatic acetyl CoA links adipose tissue inflammation to hepatic insulin resistance and type 2 diabetes. Cell. 2015;160(4):745-758.

18. Perry RJ, et al. Leptin reverses diabetes by suppression of the hypothalamic-pituitary-adrenal axis. Nat Med. 2014;20(7):759-763.

19. Previs SF, Cline GW, Shulman GI. A critical evaluation of mass isotopomer distribution analysis of gluconeogenesis in vivo. Am J Physiol. 1999;277(1 pt 1):E154-E160.

20. Sano H, et al. Insulin-stimulated phosphorylation of a Rab GTPase-activating protein regulates GLUT4 translocation. JBiol Chem. 2003;278(17):14599-14602.

21. Bruss MD, Arias EB, Lienhard GE, Cartee GD. Increased phosphorylation of Akt substrate of 160 $\mathrm{kDa}$ (AS160) in rat skeletal muscle in response to insulin or contractile activity. Diabetes. 2005;54(1):41-50.

22. Taylor EB, et al. Discovery of TBC1D1 as an insulin-, AICAR-, and contraction-stimulated signaling nexus in mouse skeletal muscle. J Biol Chem. 2008;283(15):9787-9796.

23. Bogan JS. Regulation of glucose transporter translocation in health and diabetes. Annu Rev Biochem. 2012;81:507-532.

24. Bogan JS, Hendon N, McKee AE, Tsao TS, Lodish HF. Functional cloning of TUG as a regulator of GLUT4 glucose transporter trafficking. Nature. 2003;425(6959):727-733.

25. Bogan JS, et al. Endoproteolytic cleavage of TUG protein regulates GLUT4 glucose transporter translocation. J Biol Chem. 2012;287(28):23932-23947.

26. Loffler MG, et al. Enhanced fasting glucose turnover in mice with disrupted action of TUG protein in skeletal muscle. J Biol Chem. 2013;288(28):20135-20150.

27. Kim JK, et al. Redistribution of substrates to adipose tissue promotes obesity in mice with selective insulin resistance in muscle. J Clin Invest. 2000;105(12):1791-1797.

28. Wojtaszewski J, et al. Exercise modulates postreceptor insulin signaling and glucose transport in muscle-specific insulin receptor knockout mice. J Clin Invest. 1999;104(9):1257-1264.

29. O'Neill HM, et al. AMP-activated protein kinase (AMPK) $\beta 1 \beta 2$ muscle null mice reveal an essential role for AMPK in maintaining mitochondrial content and glucose uptake during exercise. Proc Natl Acad Sci U S A. 2011;108(38):16092-16097.

30. Stanford KI, Goodyear LJ. Exercise and type 2 diabetes: molecular mechanisms regulating glucose uptake in skeletal muscle. Adv Physiol Educ.
2014;38(4):308-314.

31. Virtanen KA, et al. Glucose uptake and perfusion in subcutaneous and visceral adipose tissue during insulin stimulation in nonobese and obese humans. JClin Endocrinol Metab. 2002;87(8):3902-3910.

32. Ng JM, et al. PET imaging reveals distinctive roles for different regional adipose tissue depots in systemic glucose metabolism in nonobese humans. Am J Physiol Endocrinol Metab. 2012;303(9):E1134-E1141.

33. Kersten S. Physiological regulation of lipoprotein lipase. Biochim Biophys Acta. 2014;1841(7):919-933.

34. Jaworski K, Sarkadi-Nagy E, Duncan RE, Ahmadian M, Sul HS. Regulation of triglyceride metabolism. IV. Hormonal regulation of lipolysis in adipose tissue. Am J Physiol Gastrointest Liver Physiol. 2007;293(1):G1-G4.

35. Fried SK, Russell CD, Grauso NL, Brolin RE. Lipoprotein lipase regulation by insulin and glucocorticoid in subcutaneous and omental adipose tissues of obese women and men. JClin Invest. 1993;92(5):2191-2198.

36. Costabile G, et al. Fasting and post-prandial adipose tissue lipoprotein lipase and hormonesensitive lipase in obesity and type 2 diabetes. J Endocrinol Invest. 2011;34(5):e110-e114.

37. Panarotto D, Rémillard P, Bouffard L, Maheux P. Insulin resistance affects the regulation of lipoprotein lipase in the postprandial period and in an adipose tissue-specific manner. Eur J Clin Invest. 2002;32(2):84-92.

38. Kersten S. Physiological regulation of lipoprotein lipase. Biochim Biophys Acta. 2014;1841(7):919-933.

39. Catoire M, et al. Fatty acid-inducible ANGPTL4 governs lipid metabolic response to exercise. Proc Natl Acad Sci U S A. 2014;111(11):E1043-E1052.

40. Krssak M, et al. Intramyocellular lipid concentrations are correlated with insulin sensitivity in humans: a 1H NMR spectroscopy study. Diabetologia. 1999;42(1):113-116.

41. Perseghin G, et al. Intramyocellular triglyceride content is a determinant of in vivo insulin resistance in humans: a $1 \mathrm{H}-13 \mathrm{C}$ nuclear magnetic resonance spectroscopy assessment in offspring of type 2 diabetic parents. Diabetes. 1999;48(8):1600-1606

42. Sinha R, et al. Assessment of skeletal muscle triglyceride content by (1) $\mathrm{H}$ nuclear magnetic resonance spectroscopy in lean and obese adolescents: relationships to insulin sensitivity, total body fat, and central adiposity. Diabetes. 
2002;51(4):1022-1027.

43. Randle PJ, Garland PB, Hales CN, Newsholme EA. The glucose fatty-acid cycle: its role in insulin sensitivity and the metabolic disturbancess of diabetes mellitus. Lancet. 1963;1(7285):785-789.

44. Roden M, et al. Mechanism of free fatty acidinduced insulin resistance in humans. J Clin Invest. 1996;97(12):2859-2865.

45. Dresner A, et al. Effects of free fatty acids on glucose transport and IRS-1-associated phosphatidylinositol 3-kinase activity. J Clin Invest. 1999;103(2):253-259.

46. Petersen KF, et al. 13C/31P NMR studies on the mechanism of insulin resistance in obesity. Diabetes. 1998;47(3):381-386.

47. Cline GW, et al. Impaired glucose transport as a cause of decreased insulin-stimulated muscle glycogen synthesis in type 2 diabetes. $N$ Engl J Med. 1999;341(4):240-246.

48. Perseghin G, et al. Increased glucose transportphosphorylation and muscle glycogen synthesis after exercise training in insulin-resistant subjects. NEngl JMed.1996;335(18):1357-1362.

49. Perseghin G, Ghosh S, Gerow K, Shulman GI. Metabolic defects in lean nondiabetic offspring of NIDDM parents: a cross-sectional study. Diabetes. 1997;46(6):1001-1009.

50. Petersen KF, et al. Mitochondrial dysfunction in the elderly: possible role in insulin resistance. Science. 2003;300(5622):1140-1142.

51. Lee HY, et al. Targeted expression of catalase to mitochondria prevents age-associated reductions in mitochondrial function and insulin resistance. Cell Metab. 2010;12(6):668-674.

52. Petersen KF, Dufour S, Befroy D, Garcia R, Shulman GI. Impaired mitochondrial activity in the insulin-resistant offspring of patients with type 2 diabetes. N Engl JMed. 2004;350(7):664-671.

53. Befroy DE, et al. Impaired mitochondrial substrate oxidation in muscle of insulin-resistant offspring of type 2 diabetic patients. Diabetes. 2007;56(5):1376-1381.

54. Morino K, et al. Reduced mitochondrial density and increased IRS-1 serine phosphorylation in muscle of insulin-resistant offspring of type 2 diabetic parents. J Clin Invest. 2005;115(12):3587-3593.

55 . Morino K, et al. Regulation of mitochondrial biogenesis by lipoprotein lipase in muscle of insulin-resistant offspring of parents with type 2 diabetes. Diabetes. 2012;61(4):877-887.

56. Yu C, et al. Mechanism by which fatty acids inhibit insulin activation of insulin receptor substrate-1 (IRS-1)-associated phosphatidylinositol 3-kinase activity in muscle. J Biol Chem. 2002;277(52):50230-50236.

57. Griffin ME, et al. Free fatty acid-induced insulin resistance is associated with activation of protein kinase $\mathrm{C}$ theta and alterations in the insulin signaling cascade. Diabetes. 1999;48(6):1270-1274.

58. Itani SI, Ruderman NB, Schmieder F, Boden G. Lipid-induced insulin resistance in human muscle is associated with changes in diacylglycerol, protein kinase $\mathrm{C}$, and IкB- $\alpha$. Diabetes. 2002;51(7):2005-2011.

59 . Szendroedi J, et al. Role of diacylglycerol activation of PKCtheta in lipid-induced muscle insulin resistance in humans. Proc Natl Acad Sci US A.
2014;111(26):9597-9602.

60. Kim JK, et al. Glucose toxicity and the development of diabetes in mice with muscle-specific inactivation of GLUT4. J Clin Invest. 2001;108(1):153-160.

61. Kim JK, et al. Glucose toxicity and the development of diabetes in mice with muscle-specific inactivation of GLUT4. J Clin Invest. 2001;108(1):153-160.

62. Petersen KF, et al. The role of skeletal muscle insulin resistance in the pathogenesis of the metabolic syndrome. Proc Natl Acad Sci U S A. 2007;104(31):12587-12594.

63. Petersen KF, et al. Leptin reverses insulin resistance and hepatic steatosis in patients with severe lipodystrophy. J Clin Invest. 2002;109(10):1345-1350.

64. Kim JK, Gavrilova O, Chen Y, Reitman ML, Shulman GI. Mechanism of insulin resistance in A-ZIP/F-1 fatless mice. J Biol Chem. 2000;275(12):8456-8460.

65. Kim JK, et al. Tissue-specific overexpression of lipoprotein lipase causes tissue-specific insulin resistance. Proc Natl Acad Sci US A. 2001;98(13):7522-7527.

66. Samuel VT, et al. Mechanism of hepatic insulin resistance in non-alcoholic fatty liver disease. J Biol Chem. 2004;279(31):32345-32353.

67. Qu X, Seale JP, Donnelly R. Tissue and isoform-selective activation of protein kinase $\mathrm{C}$ in insulin-resistant obese Zucker rats - effects of feeding. JEndocrinol. 1999;162(2):207-214.

68. Samuel VT, et al. Inhibition of protein kinase Cepsilon prevents hepatic insulin resistance in nonalcoholic fatty liver disease. J Clin Invest. 2007;117(3):739-745.

69. Raddatz K, et al. Time-dependent effects of Prkce deletion on glucose homeostasis and hepatic lipid metabolism on dietary lipid oversupply in mice. Diabetologia. 2011;54(6):1447-1456.

70. Kumashiro N, et al. Cellular mechanism of insulin resistance in nonalcoholic fatty liver disease. Proc Natl Acad Sci U S A. 2011;108(39):16381-16385

71. Magkos F, et al. Intrahepatic diacylglycerol content is associated with hepatic insulin resistance in obese subjects. Gastroenterology. 2012;142(7):1444-1446.

72. Brown JM, et al. CGI-58 knockdown in mice causes hepatic steatosis but prevents diet-induced obesity and glucose intolerance. J Lipid Res. 2010;51(11):3306-3315.

73. Cantley JL, et al. CGI-58 knockdown sequesters diacylglycerols in lipid droplets/ER-preventing diacylglycerol-mediated hepatic insulin resistance. Proc Natl Acad Sci U S A. 2013;110(5):1869-1874.

74. Romeo S, et al. Genetic variation in PNPLA3 confers susceptibility to nonalcoholic fatty liver disease. Nat Genet. 2008;40(12):1461-1465.

75. Smagris E, et al. Pnpla3I148M knockin mice accumulate PNPLA3 on lipid droplets and develop hepatic steatosis. Hepatology. 2015;61(1):108-118.

76. Peter A, et al. PNPLA3 variant I148M is associated with altered hepatic lipid composition in humans. Diabetologia. 2014;57(10):2103-2107.

77. Coate KC, et al. Hepatic glucose uptake and disposition during short-term high-fat vs. highfructose feeding. Am J Physiol Endocrinol Metab. 2014;307(2):E151-E160.

78. Turinsky J, O’Sullivan DM, Bayly BP. 1,2-Diacylglycerol and ceramide levels in insulin-resistant tissues of the rat in vivo. J Biol Chem. 1990;265(28):16880-16885.

79. Holland WL, et al. Inhibition of ceramide synthesis ameliorates glucocorticoid-, saturatedfat-, and obesity-induced insulin resistance. Cell Metab. 2007;5(3):167-179.

80. Ussher JR, et al. Inhibition of de novo ceramide synthesis reverses diet-induced insulin resistance and enhances whole-body oxygen consumption. Diabetes. 2010;59(10):2453-2464.

81. Perry RJ, et al. Reversal of hypertriglyceridemia, fatty liver disease, and insulin resistance by a liver-targeted mitochondrial uncoupler. Cell Metab. 2013;18(5):740-748.

82. Raichur S, et al. CerS2 haploinsufficiency inhibits $\beta$-oxidation and confers susceptibility to dietinduced steatohepatitis and insulin resistance. Cell Metab. 2014;20(4):687-695.

83. Turpin SM, et al. Obesity-induced CerS6dependent $\mathrm{C} 16: 0$ ceramide production promotes weight gain and glucose intolerance. Cell Metab. 2014;20(4):678-686.

84. Abel ED, et al. Adipose-selective targeting of the GLUT4 gene impairs insulin action in muscle and liver. Nature. 2001;409(6821):729-733.

85. Herman MA, et al. A novel ChREBP isoform in adipose tissue regulates systemic glucose metabolism. Nature. 2012;484(7394):333-338.

86. Stefan N, et al. Circulating palmitoleate strongly and independently predicts insulin sensitivity in humans. Diabetes Care. 2010;33(2):405-407.

87. Cao H, Gerhold K, Mayers JR, Wiest MM, Watkins SM, Hotamisligil GS. Identification of a lipokine, a lipid hormone linking adipose tissue to systemic metabolism. Cell. 2008;134(6):933-944.

88. Su X, et al. Adipose tissue monomethyl branchedchain fatty acids and insulin sensitivity: Effects of obesity and weight loss. Obesity (Silver Spring). 2015;23(2):329-334.

89. Yore Mark M, et al. Discovery of a class of endogenous mammalian lipids with antidiabetic and anti-inflammatory effects. Cell. 2014;159(2):318-332.

90. Kershaw EE, Flier JS. Adipose tissue as an endocrine organ. J Clin Endocrinol Metab. 2004;89(6):2548-2556.

91. Asano T, et al. Adiponectin knockout mice on high fat diet develop fibrosing steatohepatitis. J Gastroenterol Hepatol. 2009;24(10):1669-1676.

92. Nawrocki AR, et al. Mice lacking adiponectin show decreased hepatic insulin sensitivity and reduced responsiveness to peroxisome proliferator-activated receptor $\gamma$ agonists. J Biol Chem. 2006;281(5):2654-2660.

93. Kim J-Y, et al. Obesity-associated improvements in metabolic profile through expansion of adipose tissue. J Clin Invest. 2007;117(9):2621-2637.

94. Petersen KF, et al. Apolipoprotein C3 gene variants in nonalcoholic fatty liver disease. $\mathrm{NEngl} \mathrm{J}$ Med. 2010;362(12):1082-1089.

95. Peter A, et al. Visceral obesity modulates the impact of apolipoprotein C3 gene variants on liver fat content. Int JObes (Lond). 2012;36(6):774-782.

96. Weisberg SP, McCann D, Desai M, Rosenbaum M, Leibel RL, Ferrante AWJ. Obesity is associated with macrophage accumulation in adipose tissue. JClin Invest. 2003;112(12):1796-1808. 
97. $\mathrm{Xu} \mathrm{H}$, et al. Chronic inflammation in fat plays a crucial role in the development of obesityrelated insulin resistance. J Clin Invest. 2003;112(12):1821-1830.

98. Laurencikiene J, et al. NF- $\kappa \mathrm{B}$ is important for TNF- $\alpha$-induced lipolysis in human adipocytes. JLipid Res. 2007;48(5):1069-1077.

99. Bezaire V, Mairal A, Anesia R, Lefort C, Langin D. Chronic TNFalpha and cAMP pre-treatment of human adipocytes alter HSL, ATGL and perilipin to regulate basal and stimulated lipolysis. FEBS Lett. 2009;583(18):3045-3049.

100.Ranjit S, et al. Regulation of fat specific protein 27 by isoproterenol and TNF- $\alpha$ to control lipolysis in murine adipocytes. JLipid Res. 2011;52(2):221-236.

101.Scherer T, et al. Brain insulin controls adipose tissue lipolysis and lipogenesis. Cell Metab. 2011;13(2):183-194.

102. Scherer T, Lindtner C, Zielinski E, O'Hare J, Filatova N, Buettner C. Short term voluntary overfeeding disrupts brain insulin control of adipose tissue lipolysis. J Biol Chem. 2012;287(39):33061-33069.

103. Iwen KA, et al. Intranasal insulin suppresses systemic but not subcutaneous lipolysis in healthy humans. JClin Endocrinol Metab. 2014;99(2):E246-E251.

104.Unger RH, Cherrington AD. Glucagonocentric restructuring of diabetes: a pathophysiologic and therapeutic makeover. JClin Invest. 2012;122(1):4-12.

105. German JP, et al. Schwartz MW, and Morton GJ. Leptin activates a novel CNS mechanism for insulin-independent normalization of severe diabetic hyperglycemia. Endocrinology. 2011;152(2):394-404.

106.German JP, et al. et al. Leptin deficiency causes insulin resistance induced by uncontrolled diabetes. Diabetes. 2010;59(7):1626-1634.

107. Perry RJ, Lee S, Ma L, Zhang D, Schlessinger J, Shulman GI. FGF1 and FGF19 reverse diabetes by suppression of the hypothalamic-pituitaryadrenal axis. Nat Commun. 2015;6:6980.

108. Willecke F, et al. Lipolysis, and not hepatic lipogenesis, is the primary modulator of triglyceride levels in streptozotocin-induced diabetic mice. Arterioscler Thromb Vasc Biol. 2015;35(1):102-110.

109. Vatner DF, et al. Insulin-independent regulation of hepatic triglyceride synthesis by fatty acids. Proc Natl Acad Sci U S A. 2015;112(4):1143-1148.

110. Petersen KF, et al. Increased prevalence of insulin resistance and nonalcoholic fatty liver disease in Asian-Indian men. Proc Natl Acad Sci U S A. 2006;103(48):18273-18277.

111. Matsuzaka T, et al. Insulin-independent induction of sterol regulatory element-binding protein-1c expression in the livers of streptozotocin-treated mice. Diabetes. 2004;53(3):560-569.

112. Haas Joel T, et al. Hepatic insulin signaling is required for obesity-dependent expression of SREBP-1c mRNA but not for feeding-dependent expression. Cell Metab. 2012;15(6):873-884.

113. Stanhope KL, et al. Consuming fructose-sweetened, not glucose-sweetened, beverages increases visceral adiposity and lipids and decreases insulin sensitivity in overweight/obese humans. J Clin Invest. 2009;119(5):1322-1334.

114. Uyeda K, Repa JJ. Carbohydrate response element binding protein, ChREBP, a transcription factor coupling hepatic glucose utilization and lipid synthesis. Cell Metab. 2006;4(2):107-110.

115. Erion DM, et al. The role of the carbohydrate response element-binding protein in male fructose-fed rats. Endocrinology. 2013;154(1):36-44.

116. Nagai Y, et al. The role of peroxisome proliferator-activated receptor gamma coactivator- $1 \beta$ in the pathogenesis of fructose-induced insulin resistance. Cell Metab. 2009;9(3):252-264.

117. Bindesbøll C, et al. Liver X receptor regulates hepatic nuclear O-GlcNAc signaling and carbohydrate responsive element-binding protein activity. J Lipid Res. 2015;56(4):771-785.

118. Perry RJ, Zhang D, Zhang XM, Boyer JL, Shulman GI. Controlled-release mitochondrial protonophore reverses diabetes steatohepatitis in rats. Science. 2015;347(6227):1253-1256.

119. Petersen KF, Dufour S, Befroy D, Lehrke M, Hendler RE, Shulman GI. Reversal of nonalcoholic hepatic steatosis, hepatic insulin resistance, and hyperglycemia by moderate weight reduction in patients with type 2 diabetes. Diabetes. 2005;54(3):603-608.

120. Lim EL, Hollingsworth KG, Aribisala BS, Chen MJ, Mathers JC, Taylor R. Reversal of type 2 diabetes: normalisation of beta cell function in association with decreased pancreas and liver triacylglycerol. Diabetologia. 2011;54(10):2506-2514.

121. Francois ME, et al. 'Exercise snacks' before meals: a novel strategy to improve glycaemic control in individuals with insulin resistance. Diabetologia. 2014;57(7):1437-1445.

122. Rabol R, Petersen KF, Dufour S, Flannery C, Shulman GI. Reversal of muscle insulin resistance with exercise reduces postprandial hepatic de novo lipogenesis in insulin resistant individuals. Proc Natl Acad Sci U S A. 2011;108(33):13705-13709.

123. Brownell KD, et al. Personal responsibility and obesity: a constructive approach to a controversial issue. Health Aff (Millwood). 2010;29(3):379-387.

124. Camporez JP, et al. Cellular mechanisms by which FGF21 improves insulin sensitivity in male mice. Endocrinology. 2013;154(9):3099-3109.

125. Gaich G, et al. The effects of LY2405319, an FGF21 analog, in obese human subjects with type 2 diabetes. Cell Metab. 2013;18(3):333-340.

126.Savage DB, et al. Reversal of diet-induced hepatic steatosis and hepatic insulin resistance by antisense oligonucleotide inhibitors of acetyl-CoA carboxylases 1 and 2. JClin Invest. 2006;116(3):817-824.

127. Harriman G, Greenwood J, Bhat S, Westlin WF, Kapeller R, and Harwood HJ. Acetyl-CoA Carboxylase Inhibition by ND-630 Reduces Hepatic Steatosis and Delays Diabetes Progression in ZDF Rats. Presented at: 75th Annual American Diabetes Association Annual Scientific Session; Boston, Massachusetts, USA; June 5-9, 2015. Poster 1280-P.

128. Griffith DA, et al. Spirolactam-based acetyl-CoA carboxylase inhibitors: toward improved metabolic stability of a chromanone lead structure. JMed Chem. 2013;56(17):7110-7119.

129. Tao H, Zhang Y, Zeng X, Shulman GI, Jin S. Niclosamide ethanolamine-induced mild mitochondrial uncoupling improves diabetic symptoms in mice. Nat Med. 2014;20(11):1263-1269.

130. Boyle JP, Thompson TJ, Gregg EW, Barker LE, Williamson DF. Projection of the year 2050 burden of diabetes in the US adult population: dynamic modeling of incidence, mortality, and prediabetes prevalence. Popul Health Metr. 2010;8:29. 